A N N A L E S Annales de Bretagne et des Pays de l'Ouest

\title{
AUMONT Michel, Les corsaires de Granville. Une culture du risque maritime (1688-1815)
}

\section{David Plouviez}

\section{(2) OpenEdition}

\section{Journals}

Édition électronique

URL : http://journals.openedition.org/abpo/3092

DOI : $10.4000 /$ abpo.3092

ISBN : 978-2-7535-4275-4

ISSN : 2108-6443

Éditeur

Presses universitaires de Rennes

Édition imprimée

Date de publication : 30 juin 2015

Pagination : 166-167

ISBN : 978-2-7535-4273-0

ISSN : 0399-0826

Référence électronique

David Plouviez, « Aumont Michel, Les corsaires de Granville. Une culture du risque maritime (1688-1815)», Annales de Bretagne et des Pays de l'Ouest [En ligne], 122-2 | 2015, mis en ligne le 30 juin 2015, consulté le 10 décembre 2020. URL : http://journals.openedition.org/abpo/3092 ; DOI : https://doi.org/ 10.4000/abpo.3092 
Aumont, Michel, Les corsaires de Granville. Une culture du risque maritime (16881815), Rennes, PUR, 2013, 537 p. (préface d'André Zysberg et postface d'André Lespagnol)

Michel Aumont s'inscrit dans une actualité bibliographique très riche à propos de la guerre de course et gageons que son ouvrage saura y trouver une bonne place. Issu d'une thèse de doctorat soutenue en 2010, celui-ci repose sur un socle archivistique impressionnant, d'autant qu'il s'agissait de pallier la carence des sources locales, perdues à la suite des bombardements de la ville qui ont suivi le débarquement de juin 1944. Mobilisant la documentation du secrétariat d'État puis du ministère de la Marine aux Archives nationales et au Service Historique de la Défense à Vincennes et à Cherbourg, l'auteur a également travaillé dans près d'une dizaine de centres d'archives départementaux, où il a pu collecter petit à petit les données redonnant corps à son objet historique. L'ensemble de la démonstration est découpé en quatre parties inégales (Le port de Granville du XVII ${ }^{\mathrm{e}}$ au début du XIX ${ }^{\mathrm{e}}$ siècle/L'activité corsaire à Granville de 1688 à 1815/L'armement en course/En mer, sus à l'ennemi!) formant un livre très dense et servi par de nombreux tableaux, cartes, graphiques et figures, ces dernières reproduisant beaucoup de documents issus des archives (prospectus d'armement, affiches de vente, jugement du conseil des prises...).

L'auteur entend ici s'extraire d'une histoire anecdotique nourrissant une héroïsation à outrance de la course et, bien que l'historiographie ait abandonné ce travers depuis déjà un moment, on ne peut que s'en réjouir. Toutefois, l'introduction n'expose pas de manière suffisamment explicite l'objet et l'enjeu de l'enquête. Le panorama historiographique et bibliographique dressé par l'auteur est bien trop général et l'on en vient à s'interroger sur la pertinence d'engager une étude de la course à Granville. En indiquant d'emblée l'originalité de ce port tout en faisant le bilan des sources disponibles, Michel Aumont aurait pu davantage valoriser son approche sociale de la course qui constitue effectivement le pan le plus neuf de sa démarche, sans pour autant l'opposer aux travaux économiques qu'il considère comme déjà très nombreux. Est-ce un moyen pour justifier $a$ posteriori le manque de sources qui auraient permis d'éclairer aussi cet aspect pour Granville? Toujours est-il que non seulement l'approche économique n'a pas été systématique lorsqu'il s'est agi de travailler sur la course mais, en outre, c'est une voie qui est loin d'être épuisée. Ainsi, l'impact économique réel de la course sur un port et son arrière-pays immédiat, au delà de l'armateur, du capitaine et des matelots, reste mal connu tout comme les jeux de l'échange qui apparaissent autour du recyclage des matériaux de prises par exemple.

D'ampleur inégale, les deux premières parties du livre ont leur importance puisqu'il s'agit non seulement de présenter le port et ses activités mais également la place qu'il a occupé dans cette activité de course. Ce n'est pas le moindre des enseignements de constater que Granville fut un véritable port corsaire et qu'il occupa un rang non négligeable pendant les différents conflits du XvIII ${ }^{\mathrm{e}}$ siècle, le troisième en nombre de prises pendant la guerre d'Indépendance américaine par exemple, derrière Dunkerque et Saint-Malo (p. 188). Un paradoxe étonnant lorsqu'on prend la mesure des armateurs terre-neuvas - de loin l'activité la plus importante à Granville - effectivement engagés dans la course, à hauteur de seulement $20 \%$ selon l'auteur. Renonçant à l'argument du tempérament des Granvillais avancé dans un premier temps, et qui ne convainc pas vraiment, Michel Aumont indique qu'il faut plutôt y voir l'effet d'un outil maritimo-portuaire singulièrement peu adapté à la course - infrastructures limitées, tonnage global des navires faibles - et des armateurs globalement peu investis dans les grands réseaux financiers, même si 
ce dernier aspect souffre de quelques exceptions à l'image d'un Nicolas Deslandes ou Léonor Couraye du Parc. Pour autant, cette part des armateurs investis dans la course remet-elle en cause l'idée qu'il s'agit d'une activité de substitution en temps de guerre comme semble le suggérer l'auteur? (p. 268) Ici, il convient d'être prudent dans la mesure où la course ne prend jamais complètement le pas sur l'activité traditionnelle d'un port puisque les stratégies négociantes sont multiples et parfois cumulatives. Si l'attentisme d'une partie des armateurs est récurrente à chaque conflit, l'armement en cabotage, l'investissement dans des activités manufacturières ou la course constituent des alternatives possibles. Des données glanées pour les autres ports auraient sans doute permis de montrer qu'en l'espèce Granville n'était peut être pas aussi original.

Reste que l'exploitation par l'auteur des registres de l'inscription maritime à l'instar de son directeur de recherche, André Zysberg, fin connaisseur de cette source en France - complétés judicieusement par des archives fiscales, aboutit à la rédaction de très bonnes pages dans les troisième et quatrième parties. Il est rare de disposer d'un tableau aussi précis des équipages corsaires (p. 333-405) et de pouvoir suivre les itinéraires de certains d'entre eux. À partir d'un échantillon de 1350 parcours individuels, l'auteur restitue dans toute sa crudité le destin des marins granvillais engagés dans cette activité guerrière dont les $2 / 3$ périssent ou sont fait prisonniers. Si les résultats ne remettent pas en cause des travaux antérieurs sur ces mêmes questions, l'analyse de Michel Aumont apporte des données statistiques désormais exploitables sur la longue durée. Mais au-delà des hommes, de précieux renseignements sur les matériels (navires, armement...) sont rassemblés ici à l'image de cette analyse très précise et rare de l'artillerie présente à bord des corsaires (p. 319-331) qui offre des outils numériques permettant des comparaisons utiles avec d'autres ports et d'autres conflits.

En définitive, si l'architecture de l'ouvrage est parfois déroutante, voire redondante, et si Michel Aumont ne parvient pas toujours à mettre Granville au cœur de sa démonstration, tirant des bords entre des généralités connues et son objet historique, il reste que la démonstration livre de nombreuses données inédites, fruit d'un dépouillement patient et d'ampleur. Tout travail sur la course à l'époque moderne, sous la Révolution et l'Empire devra inclure le livre de Michel Aumont dans son analyse.

David PLOUVIEZ

SCHNAKENBOURG, Éric, Entre la guerre et la paix. Neutralité et relations internationales XVII ${ }^{-}$XVIII ${ }^{e}$ siècles, Rennes, PUR, 2013.

L'ouvrage d'Eric Schnakenbourg, maître de conférences à l'université de Nantes et spécialiste d'histoire diplomatique, traite de la neutralité et des activités maritimes des neutres en temps de guerre, question d'importance tant au niveau du droit, de la diplomatie où de l'économie.

$\mathrm{Au}$ xVIII ${ }^{\mathrm{e}}$ siècle, en raison des nombreux conflits impliquant la France, les questions relatives à la neutralité occupent une place de premier ordre dans les négociations menées par les diplomates français auprès des principaux pays neutres que sont les Provinces-Unies, le Danemark et la Suède. Il s'agit de défendre le droit à la navigation de ces puissances maritimes face aux agissements britanniques pour assurer le ravitaillement du royaume en produits stratégiques du Nord. La question de la neutralité et de ses pratiques débouche sur le concept de droit des gens et de 